\title{
Reflections on the Construction of Campus Culture in Higher Vocational Colleges in the New Era
}

\author{
Wang Jiajia ${ }^{1, a}$, Chen $\mathrm{Yu}^{1, b}$ \\ ${ }^{1}$ Taizhou Polytechnic College, Jiangsu Taizhou, China, 225300 \\ awangjiajia_99@163.com bxiaoyueryuchen@163.com
}

Keywords: Higher vocational college, Core values, Campus culture, Path choice.

\begin{abstract}
Good campus culture is the most valuable wealth in higher vocational colleges. It is necessary to deeply grasp the essence and connotation of higher vocational campus culture in the new era, always take socialist core values as the guide, and carefully create first-class material culture, spiritual and institutional culture.
\end{abstract}

\section{Introduction}

There are two main aspects, internal and external, to evaluate a university: connotation construction and extension development. A more graphic description is: one soft and one hard. The connotation construction is the soft thing, the extension development is the hard thing. Soft things are sometimes harder to get than hard ones, but lasting, such as campus culture.

\section{Good campus culture is the most valuable wealth in higher vocational colleges}

What is the most important thing in higher vocational colleges? Good teachers? Great buildings? Or good students? These are very important all, especially good teachers. Mei Yiqi of Tsinghua University said, " A place that can be called a university, is not just buildings, but the masters." $\mathrm{He}$ added: "the reason why it becomes a university is that whether there are good professors or not." Make it clear that the hallmark of a university is not a building, but a master. To run a higher vocational college well, we must have good teachers, facilities and students. The easiest thing to do is the good facilities, the hardware, the beautiful campus, that is, the buildings. One more is easier, good teachers, that is, the "master" problem. Of course, what higher vocational colleges called "masters" is not "academic masters" who are rich in learning and talented, but "skilled masters" who are skillful and practice makes perfect. The other is relatively difficult, that is, good students. Some people mistakenly believe that "those with high scores are all good students" and " those with not high scores are all not good students " This is the simplest superficial definition of "good students". While it is obvious that it is unscientific on heroes in terms of test scores, what is a good student must be further explored. However, the current situation of higher vocational education is difficult to change, and it is difficult to recruit students with higher scores. The only thing that can be done is to explore the merits, strengths and potentials of these students with low scores, to teach them according to their aptitude and to bring up them carefully.

Good teachers, good buildings, good students, are all very important, but not the most important. Whether undergraduate colleges and universities or higher vocational colleges, the most core, the most valuable, but also the most difficult to do, is to form a good culture, especially good university spirit. Good culture, good spirit, need decades, even hundreds of years of accumulation, refining, inheritance and development, need generation after generation of meticulous care and carefully built. If don't be paid attention, it will be destroyed. But its influence is the most lasting, the most thorough, the most ingrained, and invaluable to the development of a university. Many scientists and educators are deeply impressed by this. In the past hundred years, numerous scientists and educators have been paying close attention to this problem. Many experts and scholars in the fields of science, education and other fields have also discussed this problem, and have published a series of important discussions and ideas. Therefore, according to General Secretary Xi Jinpingundefineds emphasis, 
"insist on not forgetting the original, absorb the outside, face the future, transform in inheritance, transcend in study", we must build the campus culture with the characteristics of the times and higher vocational education. ${ }^{[1]}$

\section{Deeply grasp the essence and connotation of higher vocational campus culture}

The fifth president of Fudan University, the sixth president of Nottingham University in the United Kingdom, and academician of the Chinese Academy of Sciences, professor Yang Fujia, have spoken loudly about the current situation of higher education in China: our socialist university, in addition to the "building, master", need more "great love"! What is "great love"? He further elaborated: "the building is a tangible asset, the master is human resources, out of the two, I also add cultural connotations, that is, great love." In the final analysis, great love is a feeling, a culture, the most essential connotation, not superficial love, not a small favor, it is nurtured by a long cultural accumulation, to the country, the people, to the truth, to the science, to the teachers and students, the deepest and thickest love, it is basically consistent with the spirit of the socialist core values and are intrinsically related.

The real "buildings" and "masters", must have rich cultural connotations. The buildings built in the past have been built for a long time, and there are many people living in them, so there are various stories, and it has been handed down to history and culture. The buildings built now, with some cultural functions, have become architectural culture and environmental culture. In the end, every tree and bush in the campus is wild plant if it has no relationship with people, with no cultural significance, but if it has a connection with people, especially celebrities and elegant people, it naturally becomes a cultural intention. In particular, the "master" itself is a kind of culture. What is the meaning of "master"? At the time of master of Chinese culture, Ji Xianlin death, Guangming Daily published a memorial article "combing our spiritual homeland in the process of saying goodbye to the master". There was a saying: "Master is not an author with many works to his credit, not disciples all over the world. Master, infiltrates his words and deeds, his thoughts and realm into our spirit, and transform our spirit." From it, we can realize that the most precious thing in the university is the spirit and the realm of conducting oneself, doing things and doing knowledge of the masters. This kind of realm, way of life, style of life condenses into a kind of invisible, untouchable, but clearly can truly feel, the "mental aura", like the air pervading in the campus, nourishing generations of teachers and students. This profound aura, in the final analysis, is a culture. If we say that hardware is the trunk of a university, while the culture with the core values of socialism as the core is the brain and soul, it is the inherent quality of a university, which is embodied in the behavior style and campus style of all teachers and employees, is the essential force that promotes development. So, no matter from which point of view, culture is the most fundamental, the most important, no matter good teachers, good architecture, good students, ultimately all attributed to culture.

The higher vocational colleges are also the same, and in the higher vocational culture, the campus culture is the most extensive. The higher vocational campus culture is a kind of group culture which is taking the social culture as the background, taking the higher vocational school as the main existence space, taking all the teachers and students as the main body, taking all kinds of cultural activities as the main content and the campus spirit as the main characteristic. Higher vocational education is a kind of education for cultivating high quality technical talents, which has the dual attributes of "higher nature" and "professional", which determines that higher vocational colleges have the "commonness" with traditional colleges and universities, as well as their own "individuality". Therefore, the construction of campus culture in higher vocational colleges must be put forward on the basis of the accurate orientation of the basic school situation, and must be closely centered around the idea of running a school and ideal pursuit of higher vocational education, combined with the objectives and conditions of running a school. In "high" and " vocational", we should do a good job, fully reflect the characteristics of "higher vocational" and higher vocational education rules. Therefore, the campus culture of higher vocational colleges must be the campus 
culture which can embody the characteristics of occupation, the ideal of occupation, the skill of occupation, the professional ethics, the attitude of occupation, and the quality of professional humanities. However, to reflect the characteristics of higher vocational education, we should not overemphasize relying on technical education and skill education, but also pay attention to the improvement of students' overall quality so as to make the students become a person of their own creation, otherwise, it will lead to the lack of humanistic education, the students can only be a tool person.

\section{The main way to construct the first-class campus culture in higher vocational colleges}

Culture is the soul of a country, a nation and a higher vocational college. ${ }^{[2]}$ To construct the first-class campus culture in higher vocational colleges, we should stand at the height of the times, take the advanced idea with strong sense of the times and innovative as the guidance, seek the layout from the high starting point, carry on the long-term systematic plan to the campus culture construction. At present, the thought of socialism with Chinese characteristics in the new era of Xi Jinping is the basic guiding ideology of all our work, and also the fundamental guiding ideology of the construction of campus culture in higher vocational education. In the process of carrying out the construction of campus culture, we must always adhere to the guidance of the socialist ideology with Chinese characteristics of Xi Jinping in the new era, fully implement the educational policy of the Party, and always take the socialist core values as the guide. In view of the new situation, the development of higher vocational education in the new era has been innovating constantly. It is necessary to adhere to the guiding position of Marxism in ideology and to fully reflect the scientific and advanced characteristics in keeping with the times.

\subsection{Create a first-class material culture}

Material culture is a cultural phenomenon formed in the process of the construction and development of the material environment in higher vocational colleges. It is a materialized campus culture form. It is a dominant culture, including all visible and tangible cultural forms within the higher vocational college, from the gate of the school to the flowers and trees in the campus, from the ponds of the campus to the school emblem. As long as it is given a certain cultural connotation, it belongs to material culture. It is not only the material basis of constructing campus culture, but also the material carrier of campus spiritual and cultural activities. To build a first-class spiritual culture, we must adhere to the concept of people-centered development, follow the principle of " situation following function," in accordance with the demand of General Secretary Xi Jinping in the report of the 19th National Congress of the Party that "we should do our best and act according to our ability," we strived to create a material culture that Russian educationalist Sukhomlinski emphasized "let the walls of the school speak too." The starting point and destination of material and cultural construction is to cultivate and shape people, so it is necessary to put functionality and education nature in an important position so that they can meet the needs and purposes of education.

\subsection{Create a first-class campus spiritual culture}

Spiritual culture is a high generalization of the spirit of higher vocational colleges, including the idea and purpose, spiritual tradition, cultural value, school motto, collective public opinion, etc. It is a special spiritual environment and cultural atmosphere created by teachers and students. The spirit of university is the result of a university internalizing, sublimating and constantly carrying out theoretical abstraction and value condensation to its idea of running a school on the basis of long-term practice, and is the quintessence of various spiritual and cultural resources. As the core and soul, it is not only the highest goal of campus culture construction, but also the basic starting point of campus culture construction. It permeates the daily life and teaching activities of teachers, students and staff, regulates and guides the behavior style, ideal pursuit and value orientation of teachers and students, and has a leading and guiding role for material culture and system culture. To build a first-class spiritual culture, it is necessary to establish a school running goal that embodies collective values in 
higher vocational colleges under the guidance of socialist core values, and constantly optimize the idea of running a school as the train of thought, the experience of running a school and the crystallization of rational thinking. To create the unique and high-quality characteristics of the school formed in the long term work, to shape the spiritual features that conform to the traditional habits, behavior patterns and the characteristics of the group of teachers and students in higher vocational colleges, to condense the spirit of running a school in the form of school motto, school spirit, school song, etc., to consolidate and optimize the relatively stable school running style, campus fashion and cultural tradition formed in the long term education and teaching practice in higher vocational colleges.

\subsection{Create a first-class institutional culture}

The institutional culture is a culture formed by the organic combination of the external form of the system and the internal experience brought by the system. It includes a variety of written texts and unwritten conventions, and the system, as well as the behavior and attitude of the people in the treatment of the system. As explicit norms and standards, it embodies the operating procedures of institutions, regulations and models, and is a force of compulsion. A scientific and reasonable system can promote the generation of good campus culture, unreasonable and defective system will destroy good campus culture and even produce bad campus culture. To build a first-class institutional culture, we must be based on the actual practice of higher vocational colleges, in accordance with the strategic objectives of the college, the development orientation and the problems in the process of development. It should be supplemented and perfected in time to make it a system that is in line with the practice of various higher vocational colleges and can promote the good and rapid development of high vocational schools.

\section{Acknowledgement}

This research was financially supported by the Special Project on ideological and political work of philosophy and Social Sciences Research in Jiangsu Province(2017SJBFDY683), and the Key projects of Scientific Research Foundation of Taizhou Vocational and Technical College(TZYKYZD-17-4), and the Funded projects of "six groups" of talents engineering training object in propaganda culture system in Taizhou City.

\section{References}

[1] Xi Jinping. Xi Jinping talks about governing[M], Volume 2: have a high level of cultural confidence, foreign language publishing house, 2017:352.

[2] Xi Jinping. Xi Jinping talks about governing[M], Volume 2: have a high level of cultural confidence, foreign language publishing house, 2017:349. 